\title{
Blood Cholesterol and Hydrocortisone Production in Man: Quantitative Aspects of the Utilization of Circulating Cholesterol by the Adrenals at Rest and under Adrenocorticotropin Stimulation *
}

\author{
Abraham J. Borkowski, $†$ Sam Levin, Claude Delcroix, Antoinette Mahler, \\ AND VERA VERHAS + \\ (From the Service of Medicine and Clinical Investigation, Institut Jules Bordet, Centre Anti- \\ cancereux de l'Université Libre de Bruxelles, and from the Central Laboratory of \\ Nuclear Medicine, Brussels, Belgium)
}

Summary. A kinetic study of the conversion of blood cholesterol into hydrocortisone was carried out in two patients through prolonged infusions of cholesterol-4- ${ }^{14} \mathrm{C}$. The following points appear to be established by our observations :

1) The infused tracer behaved metabolically like endogenous cholesterol; it could therefore serve as a means of labeling plasma cholesterol for investigating its utilization by the adrenal cortex.

2) At rest, about $80 \%$ of hydrocortisone derived from plasma cholesterol, the other $20 \%$ thus being synthesized in situ from acetate and other unlabeled precursors.

3) Under ACTH stimulation the participation of plasma cholesterol in the synthesis of hydrocortisone was the same as at rest; the conversion of plasma cholesterol into hydrocortisone was thus proportional to the production of glucocorticosteroids by the adrenal glands.

4) The specific activities of hydrocortisone allowed us to trace its adrenal precursors including adrenal cholesterol. The kinetics of the replacement of adrenal cholesterol by plasma cholesterol underlined the functional heterogeneity of the former. The experimental data were compatible with the following model: A fraction of plasma cholesterol entering the adrenal cell is immediately available for metabolism and conversion into steroid hormones, and another fraction turns over slowly, representing some form of storage.

\section{Introduction}

That the adrenal steroids, and especially cortisol, derive largely from cholesterol has long been recognized $(1,2)$. Although the adrenal tissue possesses the enzymatic equipment for cholesterol synthesis (3), it appears from studies in the

\footnotetext{
* Submitted for publication January 10, 1966; accepted January 27, 1967.

$\dagger$ Address requests for reprints to Dr. A. J. Borkowski, Institut Jules Bordet, Centre des Tumeurs de l'Université Libre de Bruxelles, 1, rue Héger-Bordet, Bruxelles, Belgium.

$¥$ Supported in part by contract Euratom-ULB-Pisa (0.26-63-4 B.I.A.C.).
}

rat (4) and in man $(5,6)$ that the cholesterol present in the adrenal glands comes essentially from plasma. Nevertheless, cholesterol synthesized in situ could conceivably be channeled into the production of glucocorticosteroids, or cholesterol might not be an obligatory precursor of these hormones (7). We have therefore evaluated in man the extent of participation of plasma cholesterol in the production of hydrocortisone. The contribution of plasma cholesterol was found to average $80 \%$, at rest as well as under ACTH stimulation. This figure is comparable to that observed by Werbin and Chaikoff in the guinea pig (8) ; they demonstrated that approximately $60 \%$ 
of hydrocortisone derives from blood cholesterol and that corticotropin does not modify this ratio.

In addition, our work, which is based on a quantitative, human, in vivo study of the transformation of plasma cholesterol into glucocorticosteroids, underlines the functional heterogeneity of both plasma and adrenal cholesterol. Our experimental data provide the basis for an understanding of the metabolism and storage of plasma cholesterol in the adrenal gland: a hypothesis in the form of a model will be presented.

\section{Methods}

\section{Labeled cholesterol and method of administration}

Cholesterol-4- ${ }^{14} \mathrm{C},{ }^{1}$ carrier free, was administered intravenously in tracer amounts as a very dispersed suspension in ethanol and water. The specific activities of cholesterol $-{ }^{1 \mathrm{C}} \mathrm{C}$ as received varied from 50 to $65 \mu \mathrm{c}$ per $\mathrm{mg}$, and the radiochemical purity amounted to 99 to $101 \%$. No further purification was carried out before use. The tracer was dissolved in $9 \mathrm{ml}$ ethanol added to $1 \mathrm{~L}$ of a $5 \%$ glucose solution in distilled water. This was infused intravenously, at a constant rate (approximately $0.8 \mathrm{ml}$ per minute) for 8 days by means of a Sigmamotor pump; the infusion bottle was changed every day. The approximate amount of radioactivity administered was calculated from the number of disintegrations per minute per milliliter of the infused solution counted at the beginning and at the end of each infusion bottle. That this calculation is approximate is not of major importance, since the only purpose of the infusion was to obtain a regular variation of the specific activity of plasma cholesterol during prolonged periods of time. The total amount of the administered radioactivity varied from 120 to $180 \mu \mathrm{c}$.

\section{Patients}

The conversion of blood cholesterol into hydrocortisone was studied in two patients with short life expectancy confined to bed but in good general condition with normal vital functions. Although their adrenal function was normal by the usual laboratory and clinical criteria, the possibility cannot be excluded that these patients may have been under some stress during the weeks preceding the study; their adrenal cortex may therefore have been delipidated to various extents.

\section{Measurements of labeled cholesterol in patients}

The concentration and specific activity of free and total plasma or serum cholesterol were measured every day. Blood was drawn between 8 and 9 a.m., before breakfast, and each sample was analyzed within 2 days after the collection. In patient A. So. the measurements were done on plasma obtained from blood collected on Versene, and in patient $\mathrm{J}$. Sch. on plasma collected on heparin.

\footnotetext{
${ }^{1}$ Radiochemical Centre, Amersham, England.
}

Two ml of plasma or serum was extracted with $50 \mathrm{ml}$ of acetone-ethanol $(1: 1$, vol: vol $)$, and samples were taken for the determination of the concentration and specific activity of free and total cholesterol. The concentration was measured by the method of Sperry and Webb (9). For the determination of the specific activity, portions of the digitonide precipitates were measured by the same method; other portions were dissolved in $2 \mathrm{ml}$ methanol and counted in a Packard model 3324 liquid scintillation counter after the addition of $18 \mathrm{ml}$ of scintillation solution as described by Chobanian and Hollander (5). Each sample was counted on two different channels, and each specific activity was expressed in disintegrations per minute per milligram after correction for efficiency, which averaged 70 to $80 \%$. The samples were counted twice, and the difference in counting for each sample was smaller than $5 \%$. Each measurement was done in duplicate; the results were within $5 \%$ of each other. No significant esterification of blood cholesterol was found to take place in vitro during the time the samples remained at room temperature. The specific activities of the cholesterol esters were calculated from the concentrations and specific activities of corresponding free and total cholesterols. In both patients $\mathrm{A}$. So. and J. Sch. the specific activities of free red cell cholesterol were similarly determined.

\section{Measurements of the specific activities of cortisol and cortisol metabolites in urine}

Twenty-four-hour urine specimens were collected every day at 8:30 a.m. A variable fraction was analyzed for the specific activities of tetrahydrocortisol (THF), tetrahydrocortisone (THE), and, when ACTH was given to the patients, also of cortisol (F) itself. ${ }^{2}$ The urine was hydrolyzed and extracted as described by Drucker, Sfikakis, Borkowski, and Christy (10). Chromatographic separation of THF, THE, and F was obtained in aluminum tanks (height $100 \mathrm{~cm}$ ) on Whatman 1 paper (width $20 \mathrm{~cm}$ ). Two systems were used successively: first the ethylene dichloride/formamide system of Burton, Zaffaroni, and Keutmann (11) (4- to 5-day run) and thereafter the Bush $B_{5}$ system (12) (2- to 3-day run). A second run on $B_{5}$ was sometimes considered necessary. A third chromatography on the $E_{4}$ system of Eberlein and Bongiovanni (13) (during 5 to 6 days) did not modify the specific activities obtained after the $B_{5}$ run. A variable fraction of the purified steroids was measured quantitatively by the Porter and Silber reaction, as described by Drucker and co-workers (10), on increasing samples; the values for color absorbancy, after Allen correction, were always compared with those obtained for the corresponding standards. ${ }^{3}$ Another fraction of

2 Cortisol : $11 \beta, 17 \alpha, 21$-trihydroxy-4-pregnene-3,20 dione; tetrahydrocortisol: $3 \alpha, 11 \beta, 17 \alpha, 21$-tetrahydroxy-pregnane20-one; tetrahydrocortisone: $3 \alpha, 17 \alpha, 21$-trihydroxy-pregnane-11,20-dione.

${ }^{3} \mathrm{We}$ are grateful to $\mathrm{Mr}$. Lewis H. Sarett of Merck and Co., Rahway, N. J., for the generous supply of tetrahydrocortisone and tetrahydrocortisol. 
the eluted steroids was counted in the liquid scintillation counter as described for plasma cholesterol on 100 to 800 $\mu \mathrm{g}$ of material. The specific activities obtained for each urinary steroid were corrected for molecular weight differences in order to match the specific activities of plasma cholesterol on a mole per mole basis; they were therefore expressed in disintegrations per minute per milligram of cholesterol. The isolated metabolites of hydrocortisone were considered to be pure when the specific activities of the THE and THF (and F when ACTH was given) were identical within the experimental error of $5 \%$.

Comparison in time of the specific activities of plasma cholesterol, adrenal cholesterol, and secreted hydrocortisone: analysis in terms of precursor-product relationships

The specific activities of adrenal cholesterol and of hydrocortisone were inferred from those of the urinary steroids. On the other hand, the renewal of adrenal cholesterol by plasma cholesterol and its conversion into steroid hormones were analyzed mathematically according to certain models. These two points will be considered separately.

Specific activities of hydrocortisone and adrenal cholesterol. The specific activities of the urinary metabolites are the mean specific activities of hydrocortisone itself for the corresponding 24-hour period. Since the secretion of hydrocortisone precedes by several hours its reduction by the liver and excretion in the urine as conjugated THE and THF, the specific activities of the latter were plotted ahead of time in order to be compared on the graphs with the specific activities of the cholesterol sample drawn at the beginning of the urine collection.

This 12-hour displacement of the urinary steroid specific activities, although arbitrary, appears reasonable, since it is known from fractional urinary collections after acute cortisol injections in man that this is approximately the time necessary for the major part of cortisol to be metabolized and excreted (14).

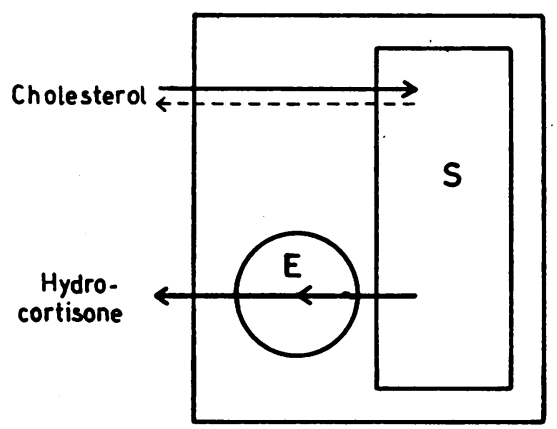

a
If the duration of the synthesis of hydrocortisone is very short and for all practical purposes, negligible, the specific activities of adrenal cholesterol available for steroidogenesis can be considered as equal to those of hydrocortisone provided that cholesterol is an obligatory precursor of the hormone.

Analysis of the experimental data in terms of precursorproduct relationships. The contribution of plasma cholesterol to cortisol biosynthesis was obtained by comparing the specific activities of these two steroids at isotopic equilibrium. This contribution was found to be very constant and allowed us to calculate at any time the theoretical specific activity of hydrocortisone if plasma cholesterol was, the only precursor of the hormone.

On the other hand, the comparison of the specific activities of plasma cholesterol and of its adrenal derivatives during cholesterol- ${ }^{\text {"1C }} \mathrm{C}$ administration and shortly thereafter permits us to follow in time the renewal of adrenal cholesterol by plasma cholesterol and its conversion into hydrocortisone provided that this hormone derives exclusively from plasma cholesterol. The kinetics of this conversion of plasma cholesterol were analyzed with an Applied Dynamics AD24 analog computer according to the following hypotheses.

First hypothesis: Free or total plasma cholesterol enters a homogeneous pool of adrenal cholesterol before being converted into hydrocortisone. This model is outlined in Figure la by one single compartment and can be expressed by the following equation:

$$
\frac{d g(t)}{d t}=k[f(t)-g(t)]
$$

where $g(t)=$ specific activities of hydrocortisone or adrenal cholesterol or both, $f(t)=$ specific activities of free or total plasma cholesterol, $k=$ fractional turnover of adrenal cholesterol, and $k=\rho / S$, where $\rho$ represents the exchange of cholesterol between plasma and the adrenals or the secretion of hydrocortisone or both, expressed in moles per unit of time, and $S$ represents the

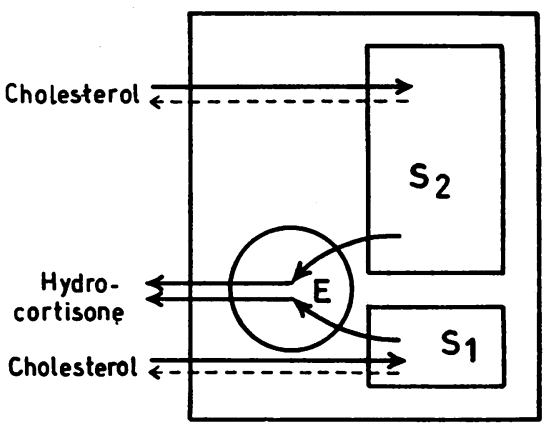

b

Fig. 1. Models Representing the possible distribution of ADRENAL Cholesterol, ITS RENEWAL BY PLASMA CHOLESTEROL, AND ITS CONVERSION TO HYDROCORTISONE. S, adrenal cholesterol; $S_{1}$ and $S_{2}$, rapidly and slowly turning over compartments; and $\mathrm{E}$, enzymes transforming cholesterol into glucocorticosteroids; the dotted lines represent a facultative return of cholesterol from the adrenal cell into the circulation. 
dimensions of the adrenal compartment expressed in moles of cholesterol.

The experimental function $f(t)$ was simulated by a diode function generator and introduced in the electronic circuitry reproducing Equation 1 . By varying $k$ from 10 to 0.025 an abacus of the function $g(t)$ was obtained (see Figures 3 and 7 for free plasma cholesterol), and these computed curves could be compared to the curve of the specific activities of hydrocortisone obtained experimentally.

Second hypothesis: Free or total plasma cholesterol entering the adrenal cell is distributed among many pools of adrenal cholesterol which turn over at different speeds but which can be grouped in two categories according to the rapidity of their renewal. This model is outlined in Figure 1b by two compartments turning over in parallel. The turnovers of the compartments $S_{1}$ (rapidly renewed) and $S_{2}$ (slowly renewed) are expressed by the following equations, respectively:

$$
\frac{d g_{1}(t)}{d t}=k_{1}\left[f(t)-g_{1}(t)\right]
$$

and

$$
\frac{d g_{2}(t)}{d t}=k_{2}\left[f(t)-g_{2}(t)\right]
$$

The symbols are the same as for the first model, and subscripts refer to compartments.

The experimental function $f(t)$ was simulated again by a diode function generator. The function $g(t)$ representing the specific activities of secreted hydrocortisone or of a combination of its two immediate precursors was reconstituted in the analog computer by summation of the functions $g_{1}(t)$ and $g_{2}(t)$. The relative contribution of the two compartments to the production of the hormone was taken into account in this summation as follows :

$$
g(t)=\alpha g_{1}(t)+(1-\alpha) g_{2}(t),
$$

where $\alpha=\rho_{1} /\left(\rho_{1}+\rho_{2}\right)$ and $1-\alpha=\rho_{2} /\left(\rho_{1}+\rho_{2}\right)$. The computed curves $g(t)$ obtained mathematically from Equation 4 were compared to the curve of the specific activities of hydrocortisone obtained experimentally. However, since the number of possible combinations of the three parameters $k_{1}, k_{2}$, and $\alpha$ is infinite, an infinite number of functions $g(t)$ could be generated in the analog computer. Consequently, the following practical approach was chosen: 1) The curve that represents the solutions $g$ ( $t$ ) had to be a linear combination of two curves figuring adrenal cholesterol as one single compartment and had to be that combination corresponding best to the specific activities of the urinary steroids; nevertheless, the only $k$ investigated were those studied in the one compartment model (Figures 3 and 7 ) although we realized that intermediary values might have given a better adjustment to the experimental results. 2) The only solutions $g(t)$ analyzed were those including necessarily one of the experimental points $g$ (i) ; $g$ (i) represents the specific activities of cortisol metabolites on day $i$, arbitrarily chosen; all the couples of curves $g_{1}(t)$ and $g_{2}(t)$ were investigated provided that $\alpha$, calculable from the arbitrary point $g$ (i), had a value between zero and one. The value of $\alpha$ could be calculated by the following formula : $\alpha=\left[g\right.$ (i) $-g_{2}$ (i) $] /\left[g_{1}\right.$ (i) $-g_{2}$ (i) ], where $g$ (i) represents the specific activities of the urinary steroids on day $i$, and $g_{1}$ (i) and $g_{2}$ (i) represent the specific activities of adrenal cholesterol to be found on the same day in the compartments $S_{1}$ and $S_{2}$.

\section{Routine investigation of adrenal function}

The 17-hydroxycorticosteroid excretion was measured daily by a slight adaptation of the method of Silber and Porter (15). Two ml urine, 1,000 U $\beta$-glucuronidase, and $2 \mathrm{ml}$ acetate buffer $\mathrm{pH} 4.5$ were incubated during 24 hours at $37^{\circ} \mathrm{C}$; steroids were extracted with $25 \mathrm{ml}$ of methylene chloride and washed with $5 \mathrm{ml}$ of $0.1 \mathrm{~N} \mathrm{NaOH}$ and $5 \mathrm{ml}$ of water. A 10-ml sample of the methylene chloride solution was then extracted with $0.5 \mathrm{ml}$ of the color reagent and another $10 \mathrm{ml}$ with a blank reagent. In 79 normal persons we found by this method a mean value of $4.9 \mathrm{mg} \pm 1.85$ per day.

The 17-ketosteroids were determined daily by the method of Drekter and co-workers (16).

\section{Separation of serum lipoproteins by starch block elec- trophoresis}

Electrophoresis of serum lipoproteins was carried out on starch block (17), in $0.1 \mathrm{M}$ barbital buffer at $\mathrm{pH} 8.6$ for 48 to 72 hours. The electrophoresis block and the electrode vessels were left in the cold room $\left(4^{\circ} \mathrm{C}\right)$ during the whole procedure. The voltage was kept constant at $5 \mathrm{v}$ per cm for a current intensity of 15 to $20 \mathrm{ma}$. After protein migration, the starch block was cut into strips, each of which was extracted twice with distilled water and once with buffer solution. Samples of the extracts were used for determination of protein content according to the method of Folin as modified by Lowry, Rosebrough, Farr, and Randall (18), and cholesterol content and specific activity were measured as described above.

\section{Fractionation of plasma lipoproteins by ultracentrifugation}

Separation of plasma lipoproteins into three fractions ( $\mathrm{D}<1.019,1.019<\mathrm{D}<1.063, \mathrm{D}>1.063$ ) was carried out according to the technique of Havel, Eder, and Bragdon (19). Plasma samples $(7 \mathrm{ml}$ ) were brought to the required densities and centrifuged at $12,000 \mathrm{~g}$ for 20 hours at approximately $5^{\circ} \mathrm{C}$ in a Martin Christ Omega II preparative ultracentrifuge (rotor type 1011). Free and total cholesterol was measured in the individual fractions and its specific activity determined as described above. Samples containing insufficient cholesterol concentrations to permit accurate quantitative colorimetry were freeze-dried and redissolved into a smaller volume.

\section{Results}

\section{Patient J. Sch. (bronchial carcinoma)}

Plasma cholesterol concentrations and adrenal function. Before ACTH administration total 
plasma cholesterol ranged from 129 to $154 \mathrm{mg}$ per $100 \mathrm{ml}$ (mean $143 \mathrm{mg}$ ); free plasma cholesterol ranged from 37 to $50 \mathrm{mg}$ per $100 \mathrm{ml}$ (mean $43 \mathrm{mg}$ ). The daily urinary excretion of glucocorticosteroids ranged from 4.9 to $10.6 \mathrm{mg}$, and the mean excretion was $8.3 \mathrm{mg}$ per day. Ketosteroid excretion varied between 2.6 and $7.7 \mathrm{mg}$ per day (mean $3.9 \mathrm{mg}$ ).

One hundred fifty U of ACTH in gel form was administered daily from days 22 to 30 (Figure 2). During ACTH administration glucocorticosteroid excretion rose to a mean value of $35.3 \mathrm{mg}$ per day (range 16.3 to $59 \mathrm{mg}$ ); during the same period, the mean ketosteroid excretion was $21.3 \mathrm{mg}$ per day (range 12.5 to $27 \mathrm{mg}$ ). The mean total plasma cholesterol concentration after ACTH was $137 \mathrm{mg}$ per $100 \mathrm{ml}$, whereas that of free plasma cholesterol was $37 \mathrm{mg}$.

Contribution of plasma cholesterol to the synthesis of hydrocortisone. Sixteen $\mu \mathrm{c}$ of cholesterol-4- ${ }^{14} \mathrm{C}$ was infused daily for 8 days. The experimental results are shown in Figure 2. It can be seen that during the infusion the rise of the specific activity of free plasma cholesterol was progressive and almost linear; as soon as cholesterol${ }^{14} \mathrm{C}$ administration ceased, the specific activity fell at a diminishing rate. The specific activities of total and esterified plasma cholesterol were parallel but lower than those of free plasma cholesterol until they reached their maximum; at this point they crossed the descending curve of free plasma cholesterol specific activity; and from then on tended to remain slightly higher but followed the latter very closely.

Plasma cholesterol and cortisol metabolites reached isotopic equilibrium within 24 hours of ACTH administration (Figure 2). As will be discussed later, the obtaining of this isotopic equilibrium can probably be attributed in part to the acceleration of the turnover of adrenal cholesterol by corticotropin. During ACTH stimulation the specific activities of hydrocortisone and plasma cholesterol fell progressively; glucocorticosteroid excretion varied widely from day to day, but the ratio of the specific activities of cortisol metabolites and plasma cholesterol remained very constant,

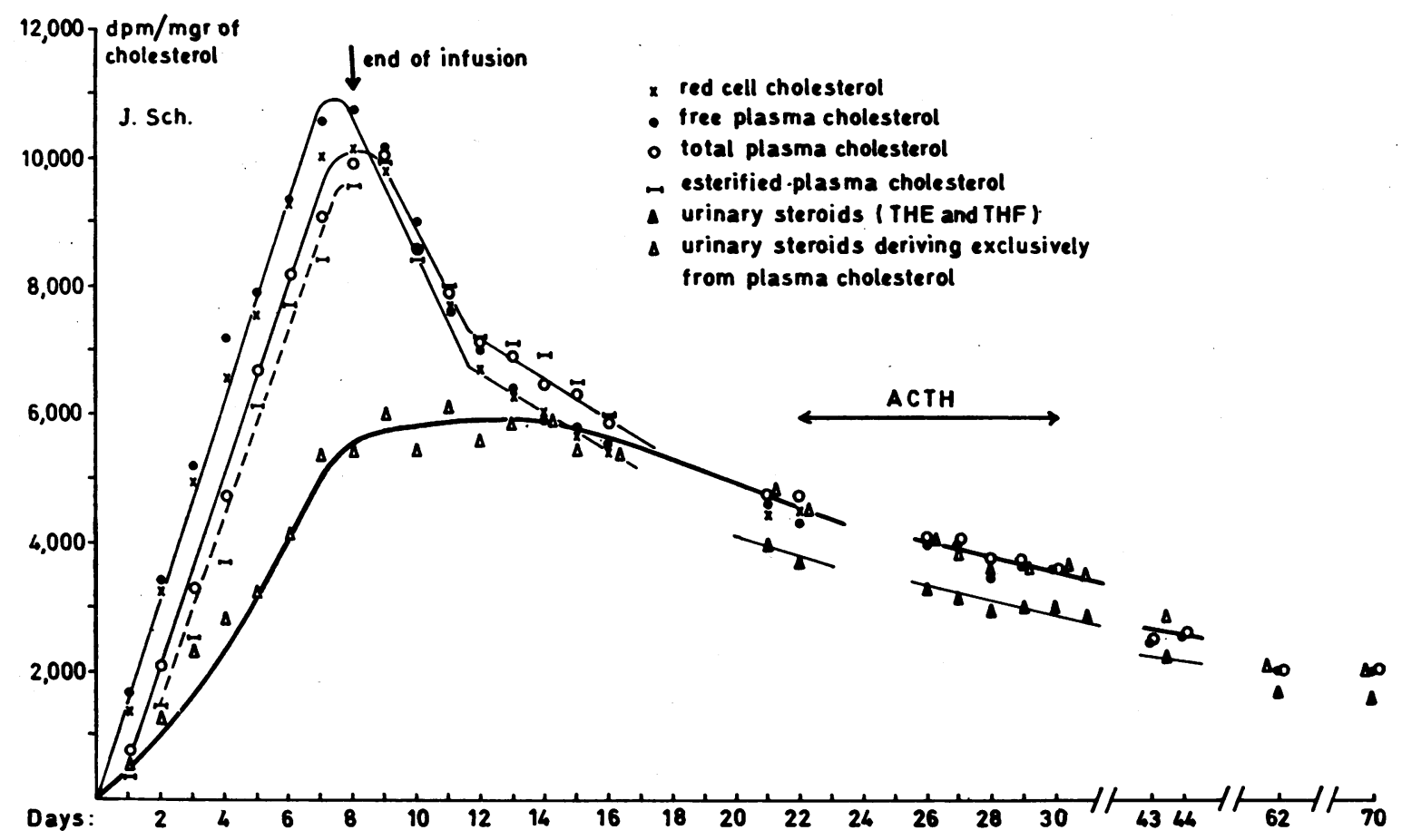

Fig. 2. The specific activities of red cell cholesterol aNd free, total, aNd esterified plasma Cholesterol COMPARED TO THOSE OF URINARY STEROIDS DURING THE INFUSION OF THE TRACER AND FOR THE FOLLOWING WEEKS. ACTH was administered from days 22 to $30 . \Delta=$ specific activities of urinary steroids, increased by $24 \%$ to account at any time for local synthesis from unlabeled precursors. THE = tetrahydrocortisone; $\mathrm{THF}=$ tetrahydrocortisol. 
averaging, respectively, 0.82 (range 0.78 to 0.85 ) and 0.80 (range 0.77 to 0.83 ) for free and total plasma cholesterol. These ratios were maintained for the following weeks at a time when glucocorticosteroid excretion had returned to normal values; 32 and 40 days after $A C T H$ administration they amounted to 0.84 and 0.79 (mean 0.82 ) for free plasma cholesterol, 0.82 and 0.78 (mean 0.80) for total plasma cholesterol.

Thus 80 to $82 \%$ of hydrocortisone derived exclusively from plasma cholesterol under conditions of normal adrenal function as well as under corticotropin stimulation. The other 18 to $20 \%$ must have been synthesized in situ from unlabeled precursors such as acetate or squalene (20) and were responsible for a 22 to $26 \%$ dilution of the specific activities of cortisol metabolites.

Kinetic studies of the utilization of plasma cholesterol by the adrenal cortex. At isotopic equilibrium the specific activities of hydrocortisone were 22 to $26 \%$ lower than those of plasma cholesterol. Because the dilution of cortisol specific activities by synthesis from unlabeled precursors was very constant, the correction for this in situ synthesis could be made at any time. In other words, the theoretical specific activities of hydrocortisone or adrenal cholesterol deriving exclusively from plasma cholesterol could be calculated at any time by increasing by $24 \%$ the specific activities of the urinary steroids. The conversion of plasma cholesterol into adrenal cholesterol and hydrocortisone could thus be followed during the first 3 weeks of this study. As can be seen in Figure 2, during cholesterol- ${ }^{14} \mathrm{C}$ administration the specific activities of THE and THF deriving from plasma cholesterol increased much more slowly than the specific activities of the latter. After the infusion, the curve of cortisol metabolites flattened out and joined the descending curve of plasma cholesterol specific activities with a delay of 6 days. These data were analyzed by analog computer according to the models outlined in Figure 1.

First model: Plasma cholesterol enters one single compartment of adrenal cholesterol (Figure 1a). The abacus of the computed curves obtained from the specific activities of free plasma cholesterol is shown in Figure 3. The fractional turnover of adrenal cholesterol was made to vary from 10 to 0.025 , but none of the computed curves fol- lowed the specific activities of hydrocortisone obtained experimentally. A similar abacus was obtained from the specific activities of total plasma cholesterol and confirmed that this model could not account for the experimental results.

Second model: Plasma cholesterol enters two compartments of adrenal cholesterol turning over in parallel (Figure 1b). The computed curves were found to fit the experimental data on the condition that the renewal of compartment $S_{1}$ be very rapid, with a fractional turnover $k_{1}$ close to $\infty$. The best computed curves obtained from free plasma cholesterol are shown in Figure 4, where the specific activity of hydrocortisone on day 8 was chosen as $g$ (i). It can be seen that the specific activities of the urinary steroids were distributed on both sides of curve 2 and that the scatter of the experimental points was usually quite moderate. According to the parameters of curve $2,28 \%$ of labeled hydrocortisone (i.e., $\alpha$ ) derived almost immediately from plasma cholesterol entering the adrenal cell $\left(k_{1} \geq 10\right)$; the remaining $72 \%$ (i.e., $1-\alpha$ ) derived from an adrenal "reservoir" the fractional turnover of which was equal to $0.200\left(k_{2}\right)$.

For total plasma cholesterol the parameters of the best computed curve were, respectively, $k_{1} \geq$ $10, \mathrm{k}_{2}=0.200$, and $1-\alpha=62 \%$. However, it must be noted that during the first 4 days of the infusion the best of the curves that could be computed from total plasma cholesterol remained systematically 10 to $25 \%$ below the specific activities of the corresponding urinary steroids; therefore, the adjustment of the model to the experimental data was not so good as for free plasma cholesterol.

Partition of cholesterol-14 $C$ between the plasma and the red cells; distribution of the tracer and of endogenous cholesterol among lipoprotein fractions. The partition of the tracer between plasma and red cells was investigated. As can be seen in Figure 2, the specific activity of free plasma cholesterol equilibrated rapidly with that of red cell cholesterol. In patient J. Sch. plasma lipoproteins were repeatedly partitioned, according to their density, by ultracentrifugation, during and after the infusion. This was done mainly in order to study the distribution of the tracer as compared to endogenous cholesterol. The specific activities 
of cholesterol in the various lipoprotein fractions are presented in Table I. As can be seen, the specific activities of free cholesterol were the same in the three fractions.

On the other hand, the specific activities of esterified cholesterol were practically always lowest in the fraction $1.019<\mathrm{D}<1.063$ and highest in fraction $\mathrm{D}>1.063$.

Similar observations were made in one other patient (Table I, patient $\mathrm{C}$. Ba., with a brain tumor) under the same experimental conditions, and it is remarkable that these differences of specific activities among lipoprotein cholesterol esters were most important during the first and second days of cholesterol-4-14 $\mathrm{C}$ infusion. These observations are in keeping with Goodman's demonstration that the turnover of esterification for endogenous cholesterol is slowest in the low density and fastest in the high density lipoproteins (21).

\section{Patient A. So. (cerebral thrombosis)}

Plasma cholesterol concentrations and adrenal function. Before ACTH administration, total plasma cholesterol ranged from 150 to $223 \mathrm{mg}$ per $100 \mathrm{ml}$ (mean $186 \mathrm{mg}$ ), and free plasma cholesterol concentrations varied between 50 and $69 \mathrm{mg}$ per $100 \mathrm{ml}$ (mean $59 \mathrm{mg}$ ). The daily glucocorticosteroid excretion, at rest, ranged from 2.9 to $7.0 \mathrm{mg}$ (mean $4.2 \mathrm{mg}$ ) ; the range of 17 ketosteroid excretion was 1.5 to $9.0 \mathrm{mg}$ per day (mean $3.1 \mathrm{mg}$ )

Twenty-five $\mathrm{U}$ of ordinary ACTH was administered intramuscularly three times a day, from days 51 to 65 . There was about a fourfold increase in the mean daily glucocorticosteroid excretion (mean $13.7 \mathrm{mg}$, range 9.1 to $23.2 \mathrm{mg}$ ). The concentrations of plasma cholesterol after corticotropin were not significantly modified (mean total cho-

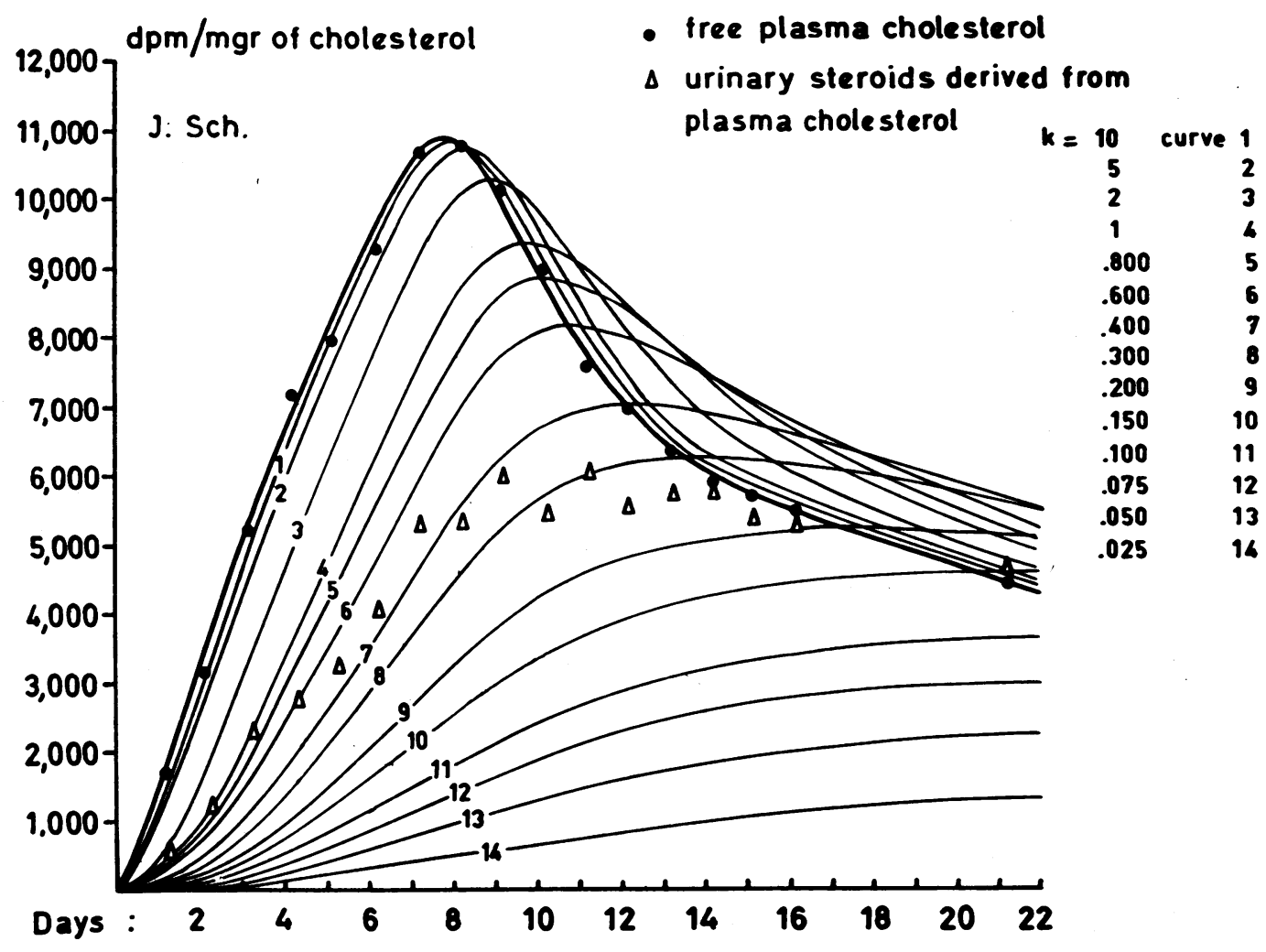

Fig. 3. POSSIBLE DISTRIBUTION OF THE SPECIFIC ACTIVITIES OF THE URINARY STEROIDS IF FREE PLASMA CHOLESTEROL WERE THE ONLY PRECURSOR AND ENTERED ONE SINGLE COMPARTMENT OF ADRENAL CHOLESTEROL. The fractional turnover $k$ of adrenal cholesterol was made to vary from 10 to 0.025 . Similar curves, not shown in this Figure, were obtained for total plasma cholesterol. No computed curve fọllowed the specific activities of cortisol metabolites obtained experimentally and corrected for in situ synthesis. 


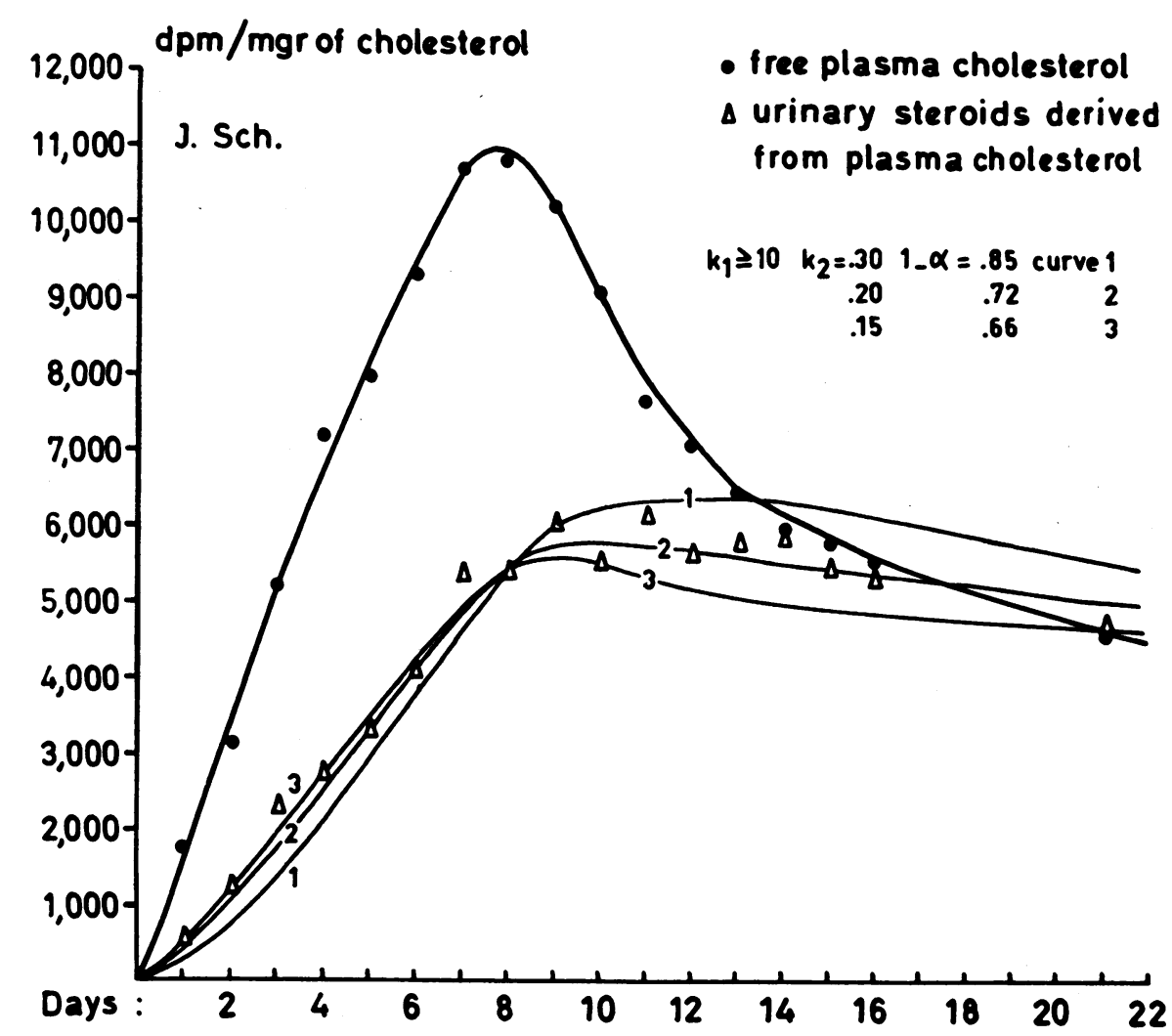

Fig. 4. Possible distribution of the SPECIfIC ACtivities of the URINARy STERoIdS IF FREe PLASMA CHOLESTEROL APPEARED IN TWO COMPARTMENTS OF ADRENAL CHOLESTEROL TURNING OVER IN PARALIEL. The three computed curves corresponding best to the specific activities of the urinary steroids are shown; their parameters are $k_{1}$ and $k_{2}$, fractional turnovers, respectively, of $S_{1}$ and $S_{2}$, whereas $1-\alpha$ represents the contribution of $S_{2}$ to the production of hydrocortisone. A similar analysis, not shown in this Figure, was carried out for total plasma cholesterol (see text).

lesterol $211 \mathrm{mg}$, mean free cholesterol $55 \mathrm{mg}$ per $100 \mathrm{ml}$ ).

Contribution of plasma cholesterol to the synthesis of hydrocortisone. In Figure 5 are plotted the specific activities of plasma cholesterol during cholesterol- ${ }^{14} \mathrm{C}$ administration and for 3 weeks thereafter. After a priming dose of $40 \mu \mathrm{c}$ given within 20 hours, which rapidly raised plasma cholesterol specific activities, about $15 \mu \mathrm{c}$ of tracer per day was infused at constant rate for 8 days. It can be seen that during the infusion the rise of the specific activity of free plasma cholesterol was progressive and almost linear; as soon as cholesterol${ }^{14} \mathrm{C}$ administration ceased, the specific activity fell at a diminishing rate. The specific activities of total and esterified plasma cholesterol were parallel but lower than those of free plasma cholesterol until they reached their maximum; at this point they crossed the descending curve of free plasma cholesterol and from then on tended to remain slightly higher but followed the latter very closely.

As in patient J. Sch. isotopic equilibrium between hydrocortisone and plasma cholesterol was reached within 48 hours of ACTH administration (Figure 6). During ACTH administration the specific activities of hydrocortisone and plasma cholesterol did not fall significantly. From days 53 to 66 the ratios of these specific activities averaged, respectively, 0.83 (range 0.74 to 0.91 ) and 0.82 (range 0.73 to 0.87 ) for free and total cholesterol. Similar ratios were still found 1 month after the end of corticotropin stimulation. On days 93 and 94 the ratios of the specific activities of cortisol metabolites and plasma cholesterol were 0.81 ( 0.77 and 0.85 ) for free and 0.80 ( 0.73 and 0.87 ) for total cholesterol, respectively. Thus 80 
TABLE I

Specific activities of cholesterol in whole plasma and in the lipoprotein fractions during and after the end of the infusion

\begin{tabular}{|c|c|c|c|c|c|c|c|c|c|c|c|c|c|c|}
\hline \multirow[b]{2}{*}{ Patient } & \multirow{2}{*}{$\begin{array}{l}\text { Day } \\
\text { during } \\
\text { infusion }\end{array}$} & \multirow{2}{*}{$\begin{array}{l}\text { Day } \\
\text { after } \\
\text { infusion }\end{array}$} & \multicolumn{3}{|c|}{$\mathrm{D}<1.019$} & \multicolumn{3}{|c|}{$1.019<\mathrm{D}<1.063$} & \multicolumn{3}{|c|}{ D $>1.063$} & \multicolumn{3}{|c|}{ Plasma } \\
\hline & & & Free & Total & Ester & Free & Total & Ester & Free & Total & Ester & Free & Total & Ester \\
\hline & & & \multicolumn{12}{|c|}{$d p m / m g$} \\
\hline \multirow[t]{5}{*}{ J. Sch. } & 3 & & 5,450 & 3,644 & 2,391 & 5,689 & 3,501 & 2,370 & 4,886 & 3,429 & 2,566 & 5,187 & 3,285 & 2,494 \\
\hline & 6 & & 9,377 & 8,238 & 7,510 & 9,037 & 7,706 & 7,263 & 9,406 & 8,228 & 7,837 & 9,302 & 8,157 & 7,680 \\
\hline & 7 & & & 9,222 & & 10,195 & 8,992 & 8,591 & 11,056 & 9,416 & 8,870 & 10,627 & 9,050 & 8,420 \\
\hline & & 1 & 11,116 & 10,474 & 10,125 & 10,861 & 9,984 & 9,661 & 10,457 & 10,171 & 10,206 & 10,146 & 10,016 & 9,959 \\
\hline & & 4 & 6,318 & 6,632 & 6,720 & 6,591 & 6,746 & 6,725 & 6,458 & 6,767 & 6,875 & 7,016 & 7,083 & 7,116 \\
\hline \multicolumn{3}{|c|}{$\begin{array}{l}\% \text { of total cholesterol in } \\
\text { the various fractions }\end{array}$} & & 11.1 & & & 69.2 & & & 19.7 & & & & \\
\hline \multirow[t]{6}{*}{ C. Ba. } & 1 & & 3,083 & 1,777 & 943 & 3,148 & 1,322 & 713 & 2,723 & 1,500 & 1,200 & 3,014 & 1,509 & 1,019 \\
\hline & 2 & & 7,996 & 5,169 & 4,098 & 5,963 & 4,667 & 3,861 & 5,976 & 5,727 & 4,943 & 7,048 & 5,038 & 4,311 \\
\hline & 3 & & 8,327 & 6,943 & 5,505 & 8,271 & 6,506 & 5,255 & 8,671 & 6,517 & 5,932 & 8,980 & 6,933 & 6,088 \\
\hline & 4 & & & 9,672 & & & 9,469 & & & 9,986 & & 11,038 & 9,759 & 9,257 \\
\hline & 6 & & 12,385 & 11,976 & 11,815 & 13,542 & 12,132 & 11,545 & 13,894 & 12,934 & 12,455 & 13,823 & 12,515 & 12,059 \\
\hline & 8 & & 15,435 & 14,071 & 13,382 & 14,927 & 13,756 & 13,174 & 15,269 & 14,340 & 13,957 & 15,625 & 14,613 & 13,282 \\
\hline \multicolumn{3}{|c|}{$\begin{array}{l}\% \text { of total cholesterol in } \\
\text { the various fractions }\end{array}$} & & 16.1 & & & 60.1 & & & 23.8 & & & & \\
\hline
\end{tabular}

to $83 \%$ of hydrocortisone derived entirely from plasma cholesterol. The other 17 to $20 \%$ must have been synthesized in situ from unlabeled precursors and was responsible for a 20 to $25 \%$ dilution of the specific activities of cortisol metabolites.

Kinetic studies of the utilization of plasma cholesterol by the adrenal cortex. As in patient J. Sch. the specific activities of hydrocortisone, at isotopic equilibrium, were 20 to $25 \%$ lower than those of plasma cholesterol. The theoretical specific activities of hydrocortisone or of adrenal cholesterol deriving exclusively from plasma cholesterol could thus be calculated at any time by increasing by $23 \%$ the specific activities of the urinary steroids. These calculated specific activities evolved like those of total plasma cholesterol (Figure 5): they reached their maximal values at the end of the infusion, then fell slowly and crossed the

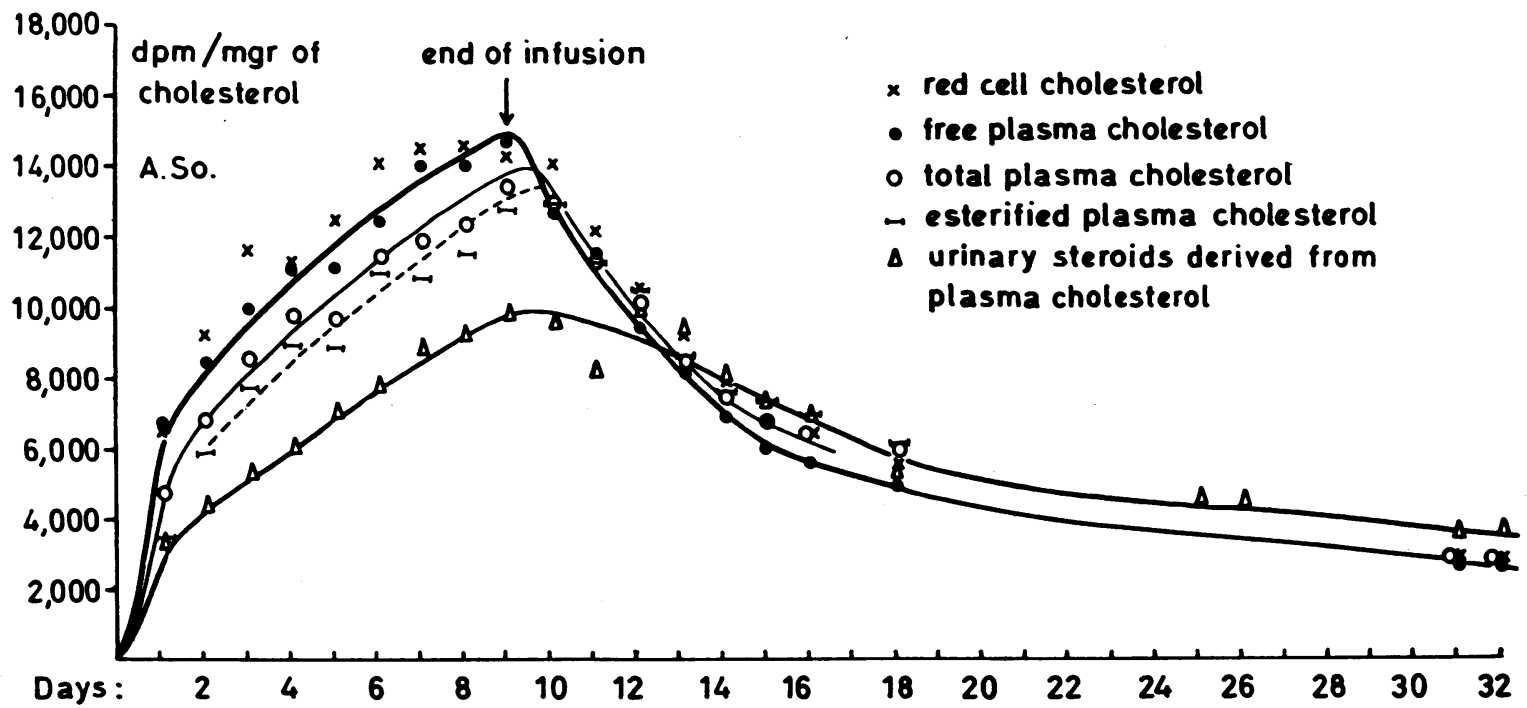

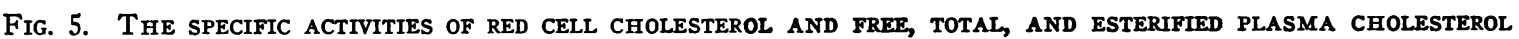
COMPARED TO THOSE OF URINARY STEROIDS DURING THE INFUSION OF THE TRACER AND FOR THE FOLLOWING WEEKS. $\Delta=$ specific activities of urinary steroids, increased by $23 \%$ to account for local synthesis from unlabeled precursors. 


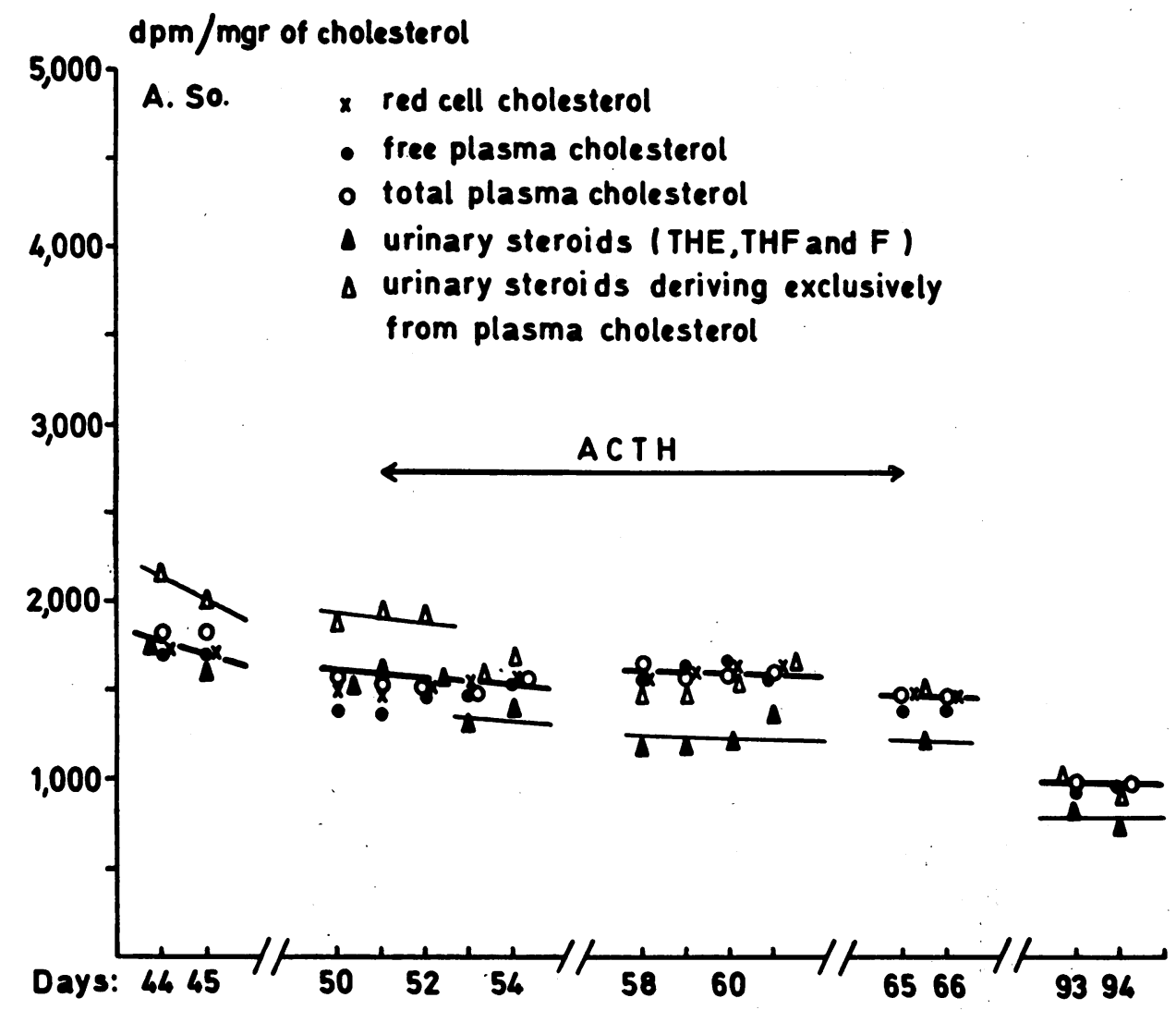

Fig. 6. Continuation of Figure 5. ACTH was administered from days 51 to 65 . $\Delta=$ Specific activities of urinary steroids, increased by $23 \%$ to account for local synthesis from unlabeled precursors. $\mathrm{F}=$ cortisol.

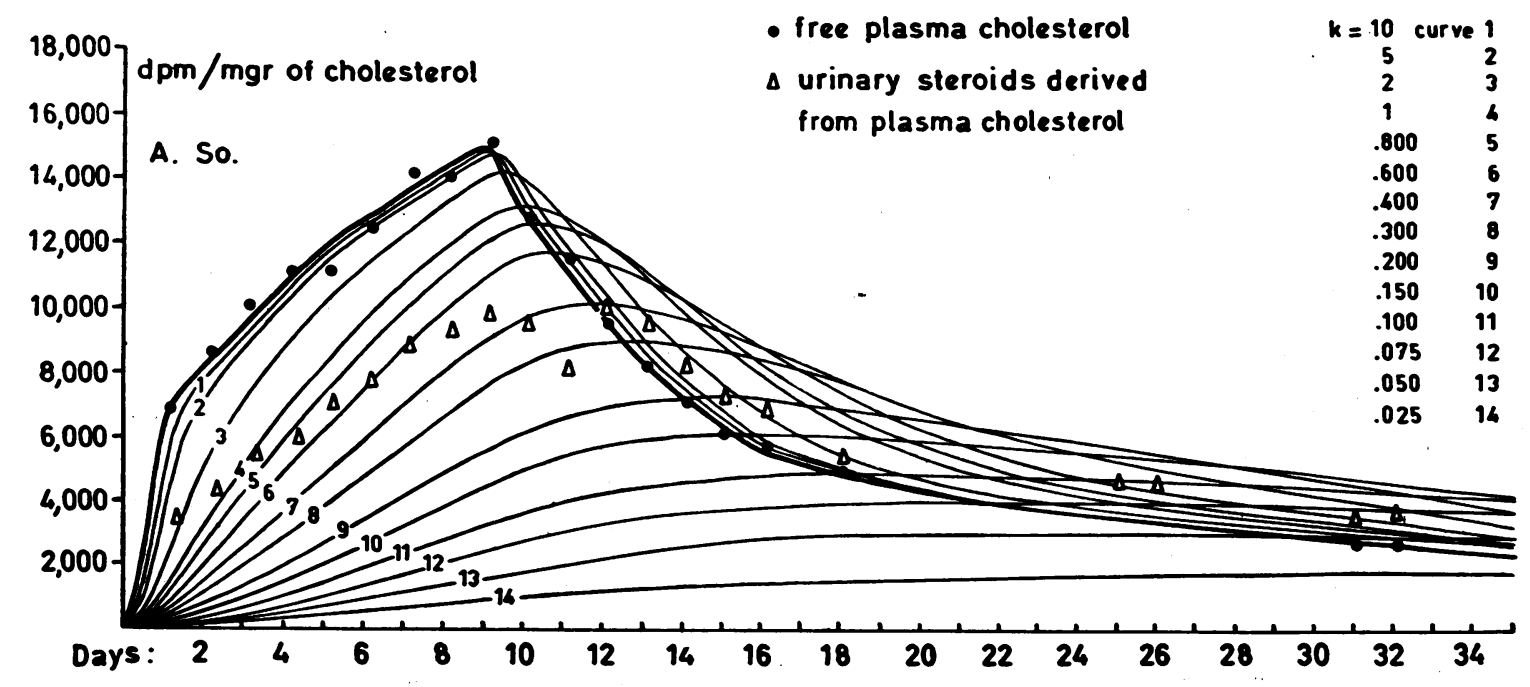

Fig. 7. Possible distribution of THE SPECIFIC ACTIVITIES OF THE URINARY STEROIDS IF FREe PLASMa CHOLESTEROL ENTERED ONE SINGLe COMPARTMENT OF ADRENAL CHOLESTERol. See legend to Figure 3. 


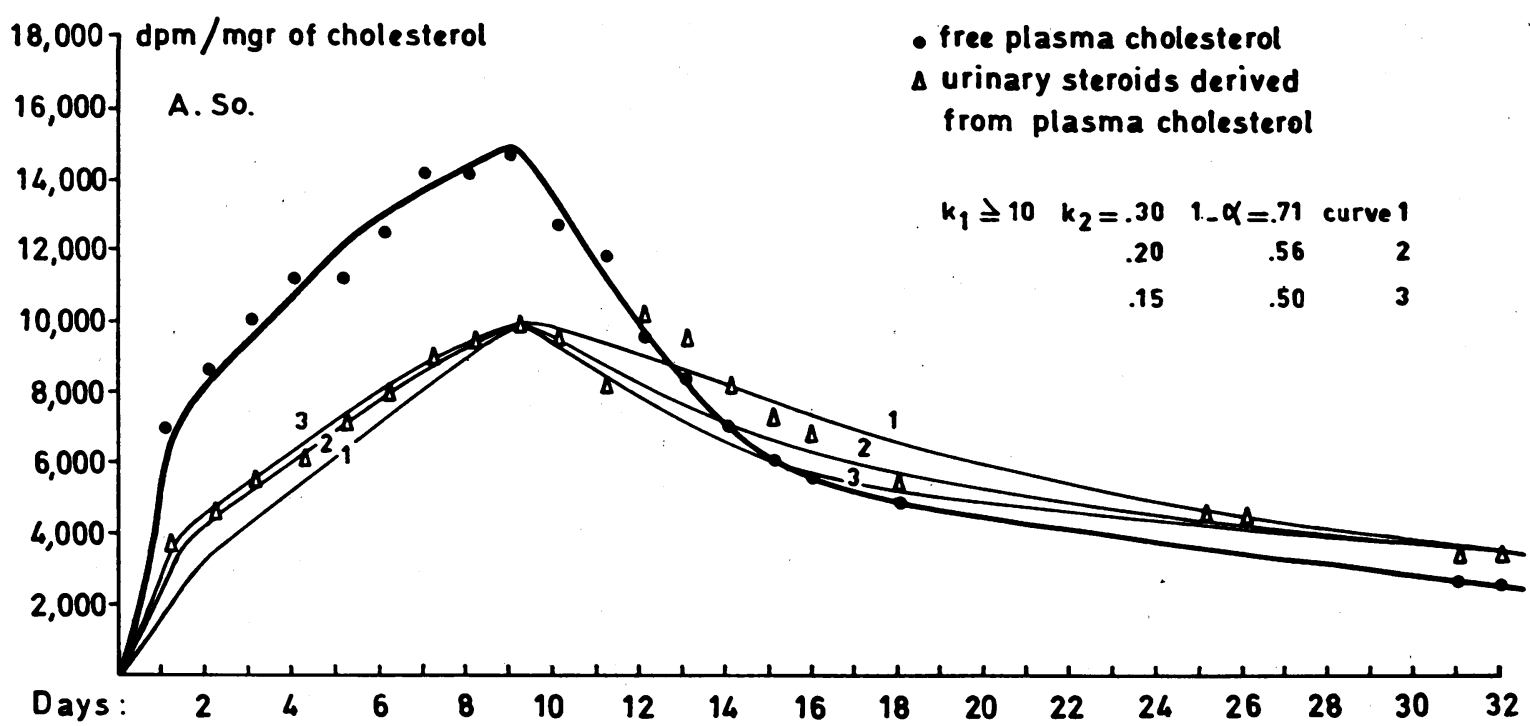

Fig. 8. PosSible distribution of the SPECIFIC ACTIVITIES OF THE URINARY STEROIDS IF FREe PLASMA CHOLESTEROL APPEARED IN TWO COMPARTMENTS OF AdRENAL CHOLESTERol tURNING OVER IN PARALLEL. See legend to Figure 4.

curve of free plasma cholesterol with a delay of 3 to 4 days; thereafter, the specific activities of the urinary steroids tended to remain higher than those of plasma cholesterol, until ACTH was administered.

The conversion of plasma cholesterol into hydrocortisone was analyzed by analog computer during the first 4 weeks of this study, and the heterogeneity of adrenal cholesterol was confirmed (Figure 7).

On the other hand, as in patient J. Sch. the experimental data were compatible with the existence of two compartments of adrenal precursors turning over in parallel on the condition that the fractional turnover of one of these compartments be close to $\infty$. The curves computed from free plasma cholesterol and corresponding best to the specific activities of hydrocortisone corrected for in situ synthesis are shown in Figure 8. According to the parameters of curve 2 , in patient A. So. $44 \%$ of labeled hydrocortisone derived almost directly from free plasma cholesterol entering the adrenal cell $\left(k_{1} \geq 10\right)$; the remaining $56 \%$ derived from free plasma cholesterol that had first been stored in a reservoir of adrenal cholesterol with a fractional turnover equal to 0.200 . With respect to total plasma cholesterol the following parameters were found to fit the experimental results: $k_{1} \geq 10, k_{2}=0.200$, and $1-\alpha=43 \%$. This curve fit the experimental results as well as

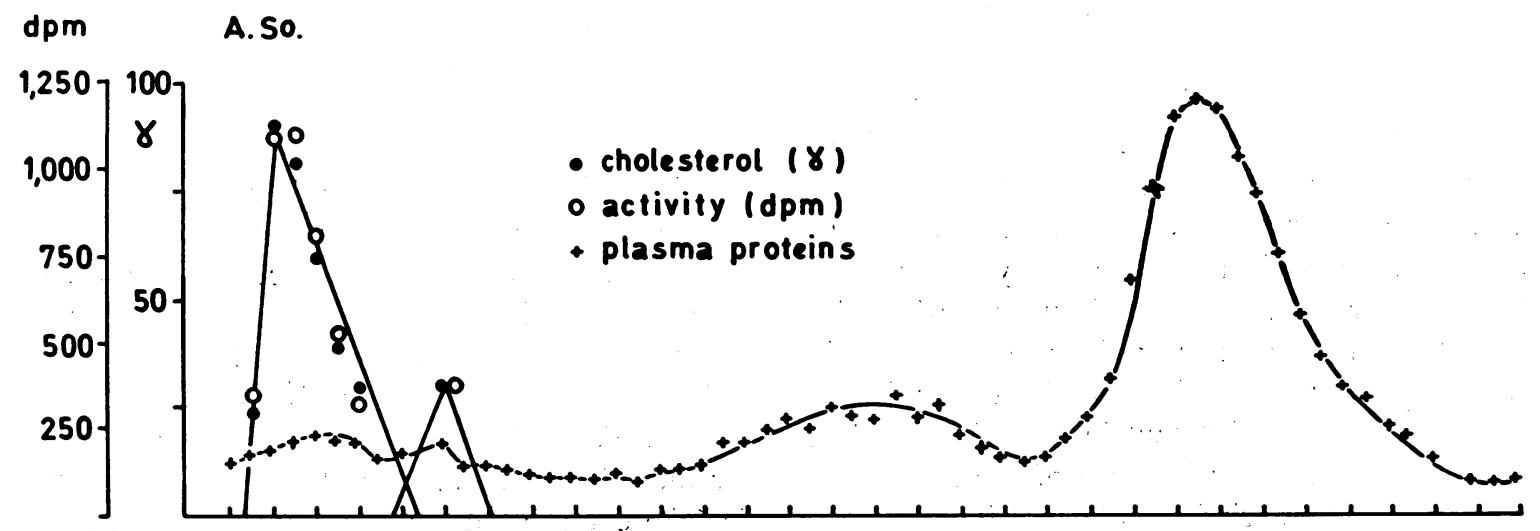

Fig. 9. Distribution of SERUM ChOlesterol aNd PROTEINS ON STARCH BLOCK ELECTROPHORESis. 
that computed from free plasma cholesterol except on the first day of the infusion; on that day the curve remained 20 to $25 \%$ below the specific activity of the urinary steroids.

Partition of cholesterol ${ }^{14} \mathrm{C}$ between plasma and red cells; distribution of the tracer and of endogenous cholesterol among serum lipoprotein fractions. Free red cell cholesterol specific activity was determined every day. As can be seen in Figure 5 the red cells equilibrated with plasma within 24 hours. On the other hand, a starch block electrophoresis of plasma lipoproteins was carried out on the last day of the infusion (Figure 9). Two lipoprotein peaks were identified. The cholesterol and the radioactivity were found to have the same distribution; the tracer was thus exclusively attached to the lipoproteins. These lipoproteins were uniformly labeled, and the specific activity of total cholesterol in the various fractions was the same as the specific activity measured in whole plasma on the same day.

\section{Discussion}

Our data are based on the use of tracer amounts of cholesterol-4- ${ }^{14} \mathrm{C}$ to study the conversion of plasma cholesterol into hydrocortisone. Three major assumptions were made in the interpretation of the data: 1) The administered cholesterol${ }^{14} \mathrm{C}$ behaves in all respects like endogenous cholesterol ; 2) the nucleus of the tracer resists chemical disruption; 3 ) the specific activities of hydrocortisone are for all practical purposes identical to those of its adrenal precursors, including adrenal cholesterol if adrenal cholesterol is an obligatory precursor of the hormone.

With respect to the first assumption, it is evident that a continuous intravenous infusion of unbound cholesterol- ${ }^{14} \mathrm{C}$ is not necessarily equivalent either to the secretion by the liver of free cholesterol bound to lipoproteins or to the return of free cholesterol from most tissues to plasma through a mechanism that has not yet been elucidated. However, constant infusions of cholesterol- ${ }^{14} \mathrm{C}$ were chosen in preference to oral or instantaneous administrations of the tracer for the following reasons: Constant infusion brings about a gradual and regular increase of the specific activity of plasma cholesterol, which permits a rough extrapolation of its progression with time from specific activities measured only once a day. Parenteral administration avoids the losses due to partial and variable absorption of the ingested cholesterol- ${ }^{14} \mathrm{C}(22)$. During the infusion, the specific activities obtained for free, esterified, and total plasma cholesterol are different from each other, since the relationships of the specific activities of free and of esterified cholesterol are those of an immediate precursor to its product. Such differences of specific activities, which are not obtained when labeled cholesterol is ingested and are very transitory in acute studies (23), provide the opportunity to determine which fraction of plasma cholesterol is the precursor of cortisol if the turnover of one compound into the other is sufficiently rapid.

The data presented in this paper provide several indications that cholesterol- ${ }^{14} \mathrm{C}$ behaved like endogenous cholesterol: 1) In starch electrophoresis of plasma it was found to be attached specifically and uniformly to the lipoproteins. 2) Labeled free cholesterol in plasma tended to equilibrate rapidly with the red cell cholesterol (24) and within the three lipoprotein fractions obtained by preparative ultracentrifugation. 3) During the infusion the specific activities of esterified cholesterol of the three lipoprotein fractions evolved in parallel but were different from each other, being lowest in the fraction $1.019<$ $\mathrm{D}<1.063$ and highest in the fraction $\mathrm{D}>1.063$. This agrees with Goodman's demonstration that the turnover of esterification for endogenous cholesterol is the least rapid in the low density and the fastest in the high density lipoproteins (21). 4) After the infusion, the fall of the specific activities of plasma free cholesterol was similar to that observed by others for endogenous cholesterol in men given acetate $-{ }^{14} \mathrm{C}(23)$. 5) The curve of the cholesterol esters was found to cross the descending curve of free cholesterol specific activities after a lapse of 1 to 2 days (23).

The second assumption concerns the stability of our tracer. One might object that the nucleus of cholesterol-4-14 $\mathrm{C}$ can be disrupted by the intestinal flora (25) and that the liberated acetate${ }^{14} \mathrm{C}$ could therefore be directly converted by the adrenal glands into cortisol. However, this factor must be negligible for at least three reasons: 1) The enterohepatic cycle of cholesterol and bile acids takes place essentially in the portion of the 
small intestine that is sterile (26). 2) The endogenous pool of acetyl coenzyme $A$ is very large and is capable of infinitely diluting such hypothetical labeled acetate. 3) It has been demonstrated that there is no radioactivity in expired $\mathrm{CO}_{2}$ after cholesterol-4- ${ }^{14} \mathrm{C}$ administration to man (23), thus indicating that the amount of acetate${ }^{14} \mathrm{C}$ liberated, if any, is quite small.

The third assumption, that cortisol and adrenal cholesterol utilized for its synthesis have the same specific activity, appears very reasonable. In such prolonged studies the duration of adrenal cholesterol conversion into hydrocortisone may be considered negligible.

Taken together these arguments support our conclusion that constant infusions of cholesterol-

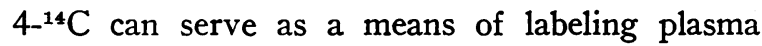
cholesterol and investigating, quantitatively, its conversion into adrenal cholesterol and hydrocortisone.

The conversion of plasma cholesterol into hydrocortisone was investigated before and after cholesterol- $\mathrm{C}^{14}$ had equilibrated between plasma and the adrenal glands. In precursor-product relationships the specific activities of the product cross those of its immediate precursor and tend to remain higher for prolonged periods of time unless the turnover of the product is accelerated (27). The acceleration of the renewal of adrenal cholesterol by plasma cholesterol does probably explain that this isotopic equilibrium was reached during ACTH administration; within 24 to 48 hours the specific activities of the urinary steroids fell to values approximately $20 \%$ below those of blood cholesterol. This difference of specific activity between blood cholesterol and cortisol metabolites was maintained through the whole period of ACTH stimulation as well as during the following weeks. It was very stable despite important variations of glucocorticosteroid excretion, and work under progress in our laboratory confirms that even under maximal stimulation by corticotropin the dilution of the specific activity of hydrocortisone compared to plasma cholesterol does not exceed the figure of about $20 \%$. This dilution must represent the synthesis in situ directly from acetate or other unlabeled precursors (20). That the contribution of this local synthesis in man is independent of the importance of glucocorticosteroid production confirms the ob- servations of Werbin and Chaikoff in the animal (8). ACTH therefore does not seem to stimulate directly the synthesis of cholesterol by the adrenal enzymes but apparently accelerates the metabolism of plasma and adrenal cholesterol into hydrocortisone.

The demonstration that $80 \%$ of hydrocortisone derived exclusively from plasma cholesterol made it possible to follow in time the functional distribution of plasma cholesterol in the adrenal glands and its conversion into steroid hormones. The kinetic studies carried out during cholesterol- ${ }^{14} \mathrm{C}$ administration and for the subsequent weeks pointed out the functional heterogeneity of adrenal cholesterol. This heterogeneity is not unexpected in view of the evidences from in vitro experiments that only a fraction of adrenal cholesterol may be rapidly available for side chain cleavage on the mitochondria (28). In our two patients the experimental data were compatible with the existence of a highly active intra-adrenal compartment where plasma cholesterol is rapidly turned over as opposed to an adrenal reservoir where plasma cholesterol is stored and slowly renewed with a turnover time of several days; the contribution of these two compartments to the synthesis of the steroid hormones and the fractional turnover of the adrenal reservoir might vary from patient to patient and somewhat from day to day.

According to this model the fate of plasma cholesterol in the adrenal cell might thus be quite analogous to that postulated for glycerophosphate and triglycerides in the adipose tissue $(29,30)$. A fraction of plasma cholesterol entering the adrenal cell could be rapidly catabolized in the cytoplasm and discharged as hydrocortisone, whereas plasma cholesterol escaping immediate catabolism could be esterified (31) and stored in the lipid droplets.

Cholesterol synthesized in situ from acetate could be channeled into the production of steroid hormones without contributing to the local reserves of precursor. This could explain that adrenal cholesterol in man seems to derive exclusively from the plasma (5). This could also explain the classic observations of Heard and his associates (7), who demonstrated on hog and rat adrenal homogenates that labeled acetate can participate in the synthesis of all the nonaromatic steroid hormones without yielding any labeled 
cholesterol. Although these interpretations have the merit of explaining the observed facts, we fully realize that they do not exclude other hypotheses based on more complicated models.

The study of the conversion of plasma cholesterol into hydrocortisone leads to a consideration of the complexity of the former. It has long been known that plasma cholesterol does not constitute a single entity; it is variably distributed among different lipoproteins, in free and esterified forms, whether of endogenous or exogenous origin, all of which may have different functions (32). One may wonder how the adrenal tissue makes the distinction among the many circulating forms of cholesterol. Our studies underline the complexity of plasma cholesterol but do not answer this question.

\section{Acknowledgments}

We are deeply indebted to Dr. Henry Tagnon without whose help and constant encouragement this work would not have been possible. For the measurements of the radioactivities we wish to thank Dr. W. Verly and the Central Laboratory of Nuclear Medicine of our University. The help of Mrs. A. M. Muller in the nursing of the patients under study has been much appreciated.

\section{References}

1. Werbin, H., and G. V. LeRoy. Cholesterol-a precursor of tetrahydrocortisone in man. J. Amer. chem. Soc. 1954, 76, 5620.

2. LeRoy, G. V. The role of cholesterol in steroidogenesis in man. Trans. Ass. Amer. Phycns 1957, 20, 202.

3. Srere, P. A., I. L. Chaikoff, and W. G. Dauben. The in vitro synthesis of cholesterol from acetate by surviving adrenal cortical tissue. J. biol. Chem. 1948, 176, 829.

4. Morris, M. D., and I. L. Chaikoff. The origin of cholesterol in liver, small intestine, adrenal gland and testis of the rat: dietary versus endogenous contributions. J. biol. Chem. 1959, 234, 1095.

5. Chobanian, A. V., and W. Hollander. Body cholesterol metabolism in man. I. The equilibration of serum and tissue cholesterol. J. clin. Invest. 1962, 41, 1732 .

6. Field, H., Jr., L. Swell, P. E. Schools, Jr., and C. R. Treadwell. Dynamic aspects of cholesterol metabolism in different areas of the aorta and other tissues in man and their relationship to atherosclerosis. Circulation 1960, 22, 547.

7. Heard, R. D. H., E. G. Bligh, M. C. Cann, P. H. Jellinck, V. J. O'Donnell, B. G. Rao, and J. L. Webb. Biogenesis of sterols and steroid hormones. Recent Progr. Hormone Res. 1956, 12, 45.
8. Werbin, H., and I. L. Chaikoff. Utilization of adrenal gland cholesterol for synthesis of cortisol by the intact normal and the ACTH-treated guinea pig. Arch. Biochem. 1961, 93, 476.

9. Sperry, W. M., and M. Webb. A revision of the Schoenheimer-Sperry method for cholesterol determination. J. biol. Chem. 1950, 187, 97.

10. Drucker, W. D., A. Sfikakis, A. J. Borkowski, and N. P. Christy. On the rate of formation of steroidal glucuronosides in patients with familial and acquired jaundice. J. clin. Invest. 1964, 43, 1952.

11. Burton, R. B., A. Zaffaroni, and E. H. Keutmann. Paper chromatography of steroids. II. Corticosteroids and related compounds. J. biol. Chem. 1951, 188, 763.

12. Bush, I. E. Methods of paper chromatography of steroids applicable to the study of steroids in mammalian blood and tissue. Biochem. J. 1952, 50, 370.

13. Eberlein, W. R., and A. M. Bongiovanni. New solvent systems for the resolution of corticosteroids by paper chromatography. Arch. Biochem. 1955, $59,90$.

14. Drucker, W. D., A. Sfikakis, A. J. Borkowski, and N. P. Christy. Unpublished observation.

15. Silber, R. H., and C. C. Porter. The determination of 17,21-dihydroxy-20-ketosteroids in urine and plasma. J. biol. Chem. 1954, 210, 923.

16. Drekter, I. J., A. Heisler, G. R. Scism, S. Stern, S. Pearson, and T. H. McGavack. The determination of urinary steroids. I. The preparation of pigment -free extracts and a simplified procedure for the estimations of total 17-ketosteroids. J. clin. Endocr. 1952, 12, 55.

17. Bloemendal, $\mathrm{H}$. Zone Electrophoresis in Blocks and Columns. Amsterdam, Elsevier, 1963.

18. Lowry, O. H., N. J. Rosebrough, A. L. Farr, and R. J. Randall. Protein measurement with the Folin phenol reagent. J. biol. Chem. 1952, 193, 265.

19. Havel, R. J., H. A. Eder, and J. H. Bragdon. The distribution and chemical composition of ultracentrifugally separated lipoproteins in human serum. J. clin. Invest. 1955, 34, 1345.

20. Goodman, DeW. S. Squalene in human and rat blood plasma. J. clin. Invest. 1964, 43, 1480.

21. Goodman, DeW. S. The in vivo turnover of individual cholesterol esters in human plasma lipoproteins. J. clin. Invest. 1964, 43, 2026.

22. Wilson, J. D., and C. A. Lindsey, Jr. Studies on the influence of dietary cholesterol on cholesterol metabolism in the isotopic steady state in man. J. clin. Invest. 1965, 44, 1805.

23. Hellman, L., R. S. Rosenfeld, M. I. Eidinoff, D. K. Fukushima, and T. F. Gallagher. Isotopic studies of plasma cholesterol of endogenous and exogenous origins. J. clin. Invest. 1955, 34, 48.

24. Hagerman, J. S., and R. G. Gould. The in vitro interchange of cholesterol between plasma and red cells. Proc. Soc. exp. Biol. (N. Y.) 1951, 78, 329.

25. Stadtman, T. C., A. Cherkes, and C. B. Anfinsen. Studies on the microbiological degradation of cholesterol. J. biol. Chem. 1954, 206, 511. 
26. Swell, L., E. C. Trout, Jr., R. Hopper, H. Field, Jr., and C. R. Treadwell. The mechanism of cholesterol absorption. Ann. N. Y. Acad. Sci. 1959, 72, 813.

27. Zilversmit, D. B. The design and analysis of isotope experiments. Amer. J. Med. 1960, 29, 832.

28. Hayano, M., N. Saba, R. I. Dorfman, and O. Hechter. Some aspects of the biogenesis of adrenal steroid hormones. Recent Progr. Hormone Res. 1956, 12, 79.

29. Wertheimer, H. E. Introduction-a perspective in Adipose Tissue, Section 5 of Handbook of Physiology, A. E. Renold and G. F. Cahill, Jr., Eds.
Washington, D. C., American Physiological Society, 1965 , p. 5 .

30. Hollenberg, C. H. The origin and glyceride distribution of fatty acids in rat adipose tissue. J. clin. Invest. 1966, 45, 205.

31. Longcope, C., and R. H. Williams. Esterification of cholesterol by homogenates of rat adrenal tissue. Endocrinology 1963, 72, 735.

32. Sakakida, H., C. C. Shediac, and M. D. Siperstein. Effect of endogenous and exogenous cholesterol on the feedback control of cholesterol synthesis. J. clin. Invest. 1963, 42, 1521. 